\title{
Escrita para Vassourinhas e sua relação com os sistemas de notação coreográfica
}

\section{Liliana Harb Bollos Nelton Essi}

\begin{abstract}
Resumo: Quando tocamos com vassourinhas, fazemos sequências de padrões de movimentos como na dança. No entanto, no caso do baterista esses movimentos emitem som. Podemos relacionar a escrita do movimento usada na dança desde 1700 com a escrita para vassourinhas de Ed Thigpen, Clayton Cameron e Kirk Wilis a fim de melhorar nossas técnicas de notação. Apesar de ter uma forte tradição oral, os coreógrafos e bailarinos também sentiram necessidade de registrar e perpetuar suas coreografias pela escrita. Analisaremos a Labanotation, Benesh Movement Notation e a Sutton Movement Shorthand. A escrita para vassourinhas ainda se encontra em movimento de evolução e é necessário que olhemos para a história para poder contribuir com ela.
\end{abstract}

Palavras-chave: Vassourinhas. Notação musical. Notação na dança. Metodologia.

Writing For Brushes and its relation with notation systems for choreography.

Abstract: When we play brushes, we make movement sequences patterns as in dance. However, the drummer movements emit sounds. We can relate the writing of movement used in dance since 1700 with the way Ed Thigpen, Clayton Cameron and Kirk Wilis wrote for brushes, in order to improve our notation techniques. Despite having a strong oral tradition, choreographers and dancers also felt the need to record and perpetuate their choreography through writing. We will review Labanotation, Benesh Movement Notation and Sutton Movement Shorthand. Writing for brushes is still in the movement of evolution and it is necessary that we look back at the history to be able to contribute to it.

Keywords: Brushes. Music notation. Dance notation. Methodology. 


\section{Notação coreográfica}

Para começarmos a falar sobre a escrita para vassourinhas, precisamos entender primeiro como e com quais elementos ela tem sido notada até hoje. Em Cameron, podemos observar frequentemente o uso do termo coreografia (choreography) tanto para designar o movimento a ser utilizado como para a mudança para outro movimento. Segundo ele "coreografia é necessária para criar um senso de tempo e espaço e também para evitar que as cerdas embaracem" (CAMERON, 2003).

O termo 'coreografia', segundo Trindade, tem contexto histórico variado. Ele é derivado da palavra coreia (xopéia), uma dança grega, dançada em círculos e acompanhada por canto. Derivações da palavra coreia são usadas para descrever danças de círculos em outros lugares: khovorod (Rússia), Hora (Romania, Moldova e Israel), Horo (Bulgária). Paracelsus usou o termo coreia para descrever os movimentos físicos rápidos dos viajantes medievais (TRINDADE, 2008, p. 29). Além disso, para Trindade, coreografia, na contemporaneidade, pode ser entendida como a estrutura de conexões entre diferentes estados corporais que figuram em uma dança e dela faz emergir seus nexos de sentidos (TRINDADE, 2008, p. 32).

Dessa forma, podemos perceber, assim como na dança, que quando tocamos com vassourinhas fazemos sequências de padrões de movimentos. No entanto, no caso do baterista, esses movimentos emitem som. Tais constatações nos fazem conjecturar a respeito de possíveis notações para coreografias de dança. Apesar de ter uma forte tradição oral, os coreógrafos e bailarinos sentiram a necessidade de registrar e perpetuar suas coreografias.

A primeira tentativa de escrever a dança foi em 1700 pelo coreógrafo e professor de dança Raoul-Auger Feuillet, que trabalhou na corte de Luiz XIV, com seu livro Choréografie ou l'art d'écrire la dance par caractères, figures et signes démonstratifs (Coreografia ou a arte de escrever a dança com caracteres, figuras e sinais demonstrativos). 
Curiosamente, ao pesquisar sobre o assunto podemos encontrar pelo menos mais oito tipos diferentes de notação usadas na dança clássica. Citaremos aqui as mais usadas atualmente: a Labanotation, a Benesh Movement Notation e a Sutton Movement Shorthand.
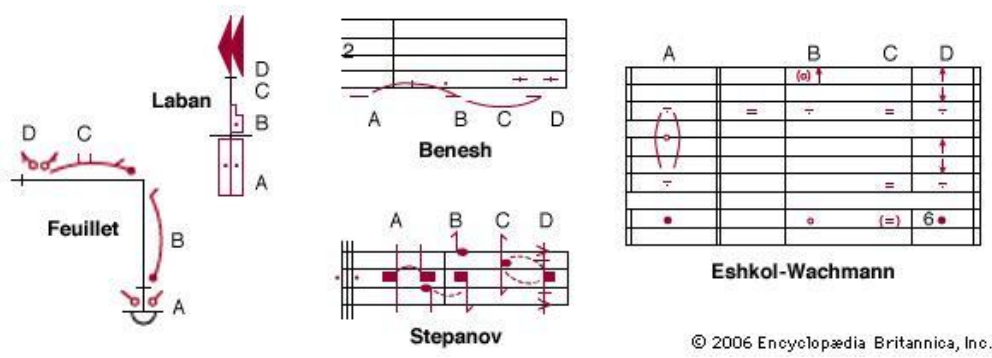

Fig. 1: Exemplificação da diferença entre as escritas de dança. Figuras recriadas a partir de notações originais (Dance notation, Encyclopedia Britannica).

\subsection{Labanotation}

A Labanotation utiliza uma escrita detalhada com a notação da ação de cada articulação do corpo com suas relações internas e externas (fora do corpo, no espaço) dos pés à cabeça. Sua escrita utiliza uma pauta vertical de três linhas cuja leitura se realiza de baixo para cima, o que nos possibilita estabelecer uma relação clara dos lados direito e esquerdo da pauta com os mesmos lados do corpo do (a) bailarino (a). As linhas horizontais mantém uma relação direta com as barras de compasso utilizadas na partitura musical. Além disso temos uma notação separada dos movimentos a serem realizados no solo. Na figura 2 temos um exemplo de partitura extraído do livro Schrifttanz de Rudolf Laban (1928), onde se tem origem do labanotation, o método de escrita da dança mais divulgado mundialmente: 


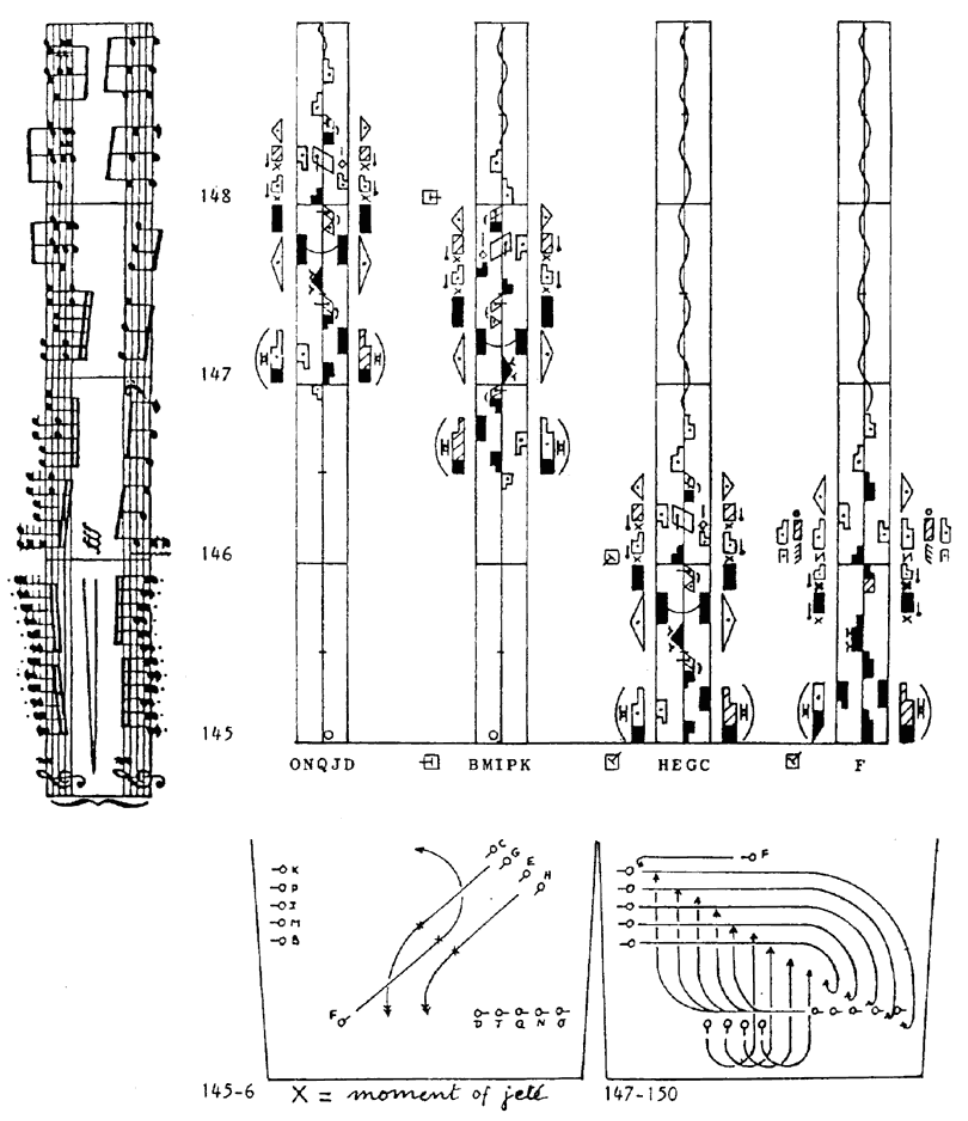

Fig. 2: Exemplo de partitura para dança (Schrifttanz, Encyclopedia Britannica).

\subsection{Benesh Movement Notation}

A notação Benesh usa os princípios da escrita musical separando as coreografias simultâneas e diferentes em pautas sobrepostas como numa grade de maestro. Usa-se o pentagrama para indicar as partes do corpo e apenas três sinais para demonstrar os movimentos: uma linha horizontal, uma linha vertical e uma bolinha. O ritmo e o fraseado do movimento são colocados acima do pentagrama e a "fórmula de compasso", que é a indicação de número de tempos ou contagens dentro 
do compasso, é colocado no início da coreografia e obriga a utilização de barras para separação dos mesmos. Na próxima figura (fig. 03), temos um exemplo de uma partitura em Benesh Movement Notation extraído do livro "Movement Study and Benesh Movement Notation" de Julia McGuinnessScott:

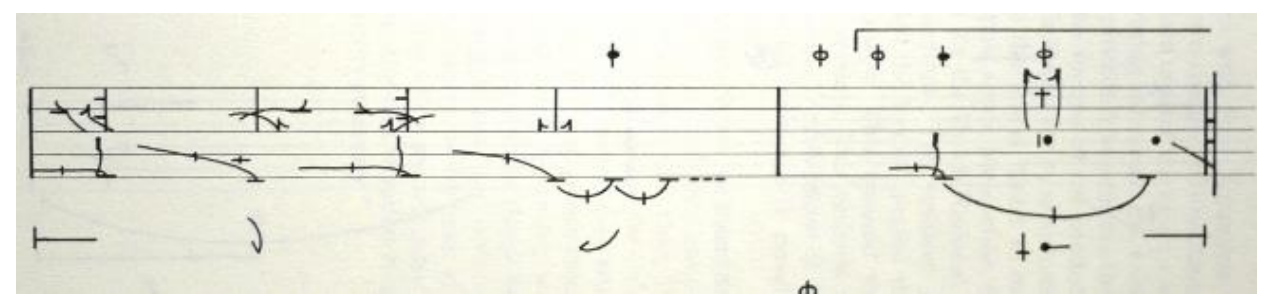

Fig. 3: Exemplo de uma partitura em benesh (MCGUINNESS-SCOTT, 1983, p. 148).

Esta notação também inclui sinais para diferenciação dos personagens e outros para a posição dos bailarinos no solo do palco compasso a compasso.

\subsection{Sutton Movement Shorthand}

O Sistema Sutton de notação é utilizado para descrever qualquer movimento do corpo humano e tem cinco ramificações: Dance Writing, Sign Writing, Mime Writing, Sports Writing e Science Writing. Nossa pesquisa se interessa pelo Dance Writing que é utilizado para descrever qualquer movimento da dança. Utiliza também o pentagrama para indicar as partes do corpo e sua posição em determinado movimento. 


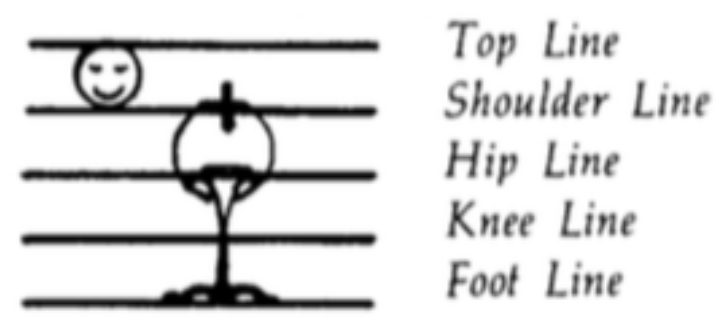

Fig. 4: Exemplificação das partes do corpo no pentagrama de Sutton (SUTTON, 1983, p. 6)

Abaixo do pentagrama usa-se um círculo maior para indicar a posição dos pés e a posição dos membros inferiores em relação ao corpo; e o círculo menor para indicar a posição da cabeça e a posição dos membros superiores em relação ao corpo. Números acima dos desenhos são colocados acima para indicar a contagem e uma fórmula de compasso é usada no início.

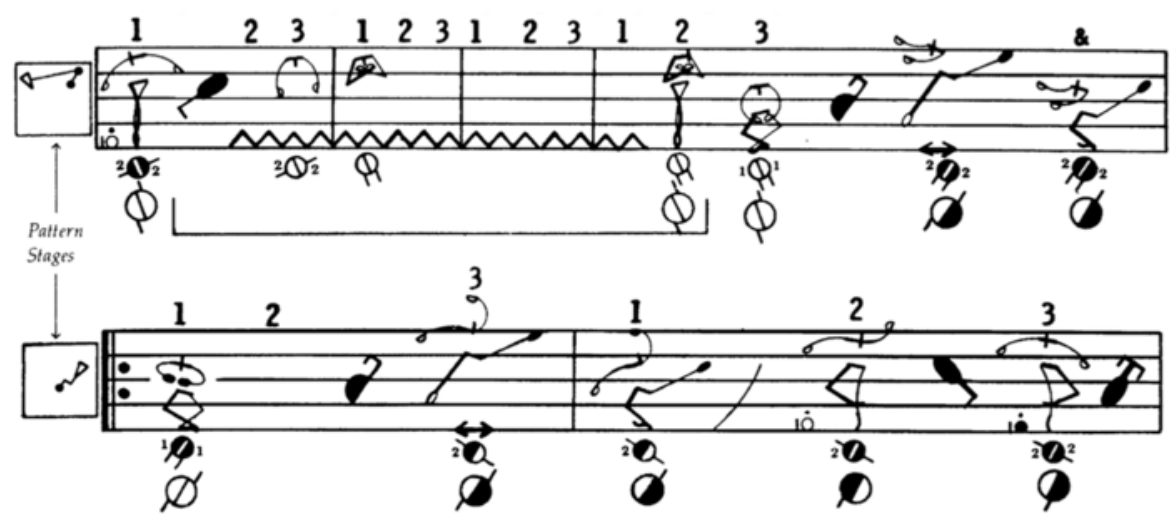

Fig. 5: Exemplo da grafia de Sutton (SUTTON, 1983, p. 7)

Os três sistemas de escrita da dança, a saber, Labanotation, Benesh Movement Notation e Sutton Movement Shorthand exigem que o bailarino 
e/ou coreógrafo aprenda uma série de símbolos que vão ampliar ainda mais a gama de especificidade da grafia das posições e movimentos.

\section{Escrita para vassourinhas}

Conseguimos estabelecer uma conexão entre a escrita do movimento na dança e a escrita para vassourinhas porque podemos ver que é possível notar o material sonoro e o coreográfico juntos. Tocar com vassourinhas exige movimentação horizontal na superfície do tambor, de forma que, ao arrastar as cerdas pela pele, produzamos um som ligado e muitas vezes contínuo. Em muitos casos podemos "criar variações de forma para tocar o mesmo ritmo" (HAZILA, 2000), em outros, se mudamos a coreografia, mesmo se estivermos tocando o mesmo ritmo, podemos mudar completamente a característica do som emitido.

A primeira publicação sobre o assunto foi do baterista Philly Joe Jones em 1968 numa publicação da Premier Drum Company. Este pequeno livro chamado Brush artistry reúne alguns de seus principais movimentos e dá início a divulgação impressa da arte de tocar com vassourinhas. 


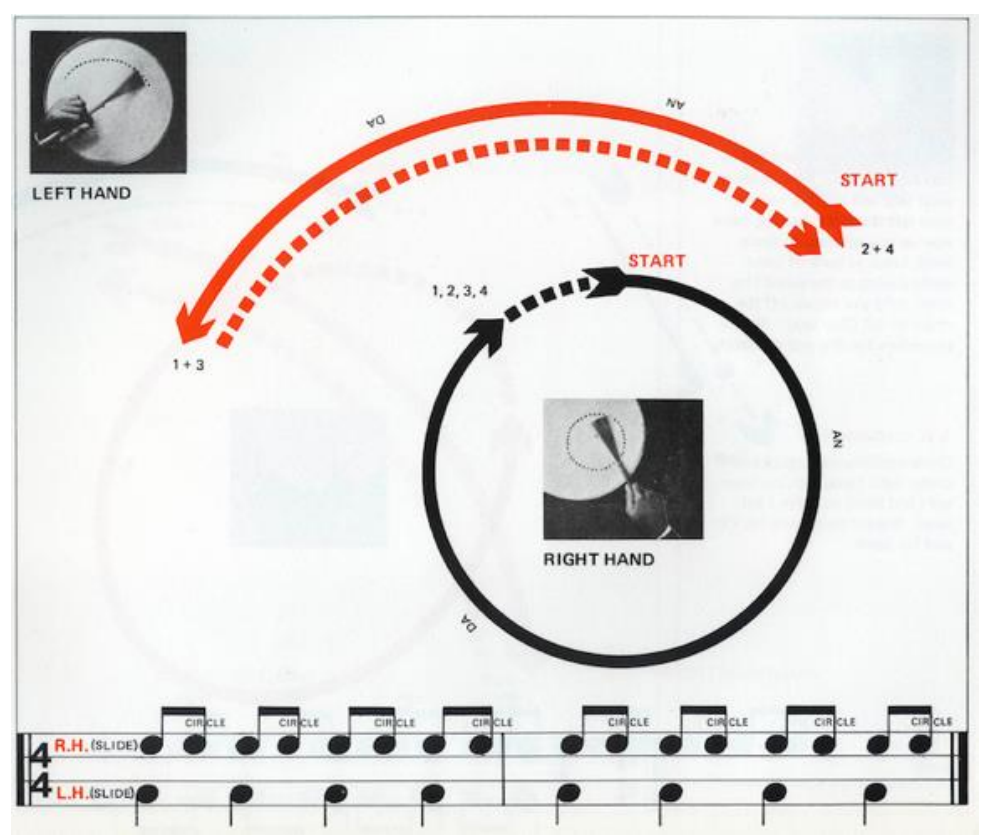

Fig. 6: Extraído do livro Brush Artitry de Philly Joe Jones (JONES, 1968, p. 2).

Pierre Conté, bailarino, coreógrafo, compositor e teórico do movimento francês, também desenvolveu um método de notação próprio em que alia ciências biomecânicas para descrição dos movimentos e escrita musical. Ele escrevia as músicas para suas próprias coreografias, usando sistema de linhas que identifica a parte do corpo. As figuras musicais no exemplo abaixo (fig. 7) são usadas para indicar o tempo de cada ação. 


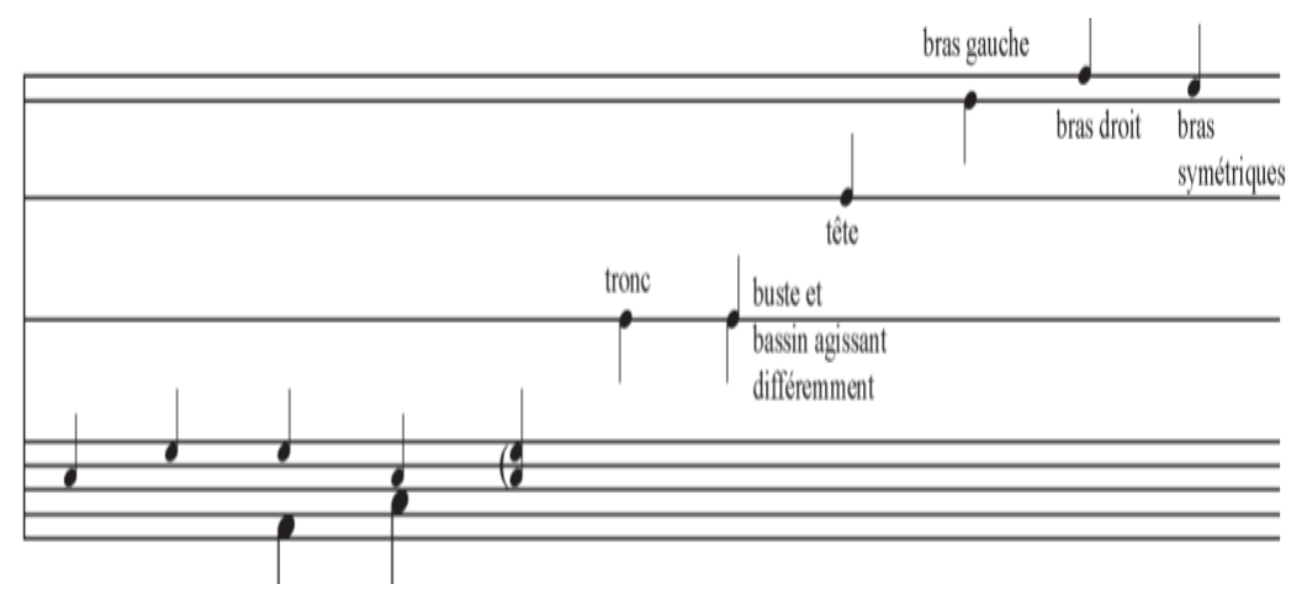

Fig. 7: Explicação legendada sobre ações de cada parte do corpo segundo P. Conté (s/d).

As mudanças de direção, constantes na dança, são muito importantes e o músico precisa estar ciente disso. "Mudança de direção cria ritmo" (CAMERON, 2003, p. 13). Portanto, saber o tipo de coreografia a ser utilizada pode ajudar muito o estudante ou profissional interessado em aprender e reproduzir um determinado padrão de movimento/som criado por um outro baterista num solo ou acompanhamento. Além disso, a mudança de direção pode ser utilizada para dar mais beleza visual ao que se toca. Os bateristas de jazz como Papa Jo Jones, Philly Joe Jones, Max Roach e praticamente todos os seus contemporâneos eram verdadeiros entertainers. Era bonito vê-los tocar. Jeff Hamilton, em uma matéria para a revista Percussive Notes, já constatava que a beleza coreográfica era importante, "You've got to be pretty when you play brushes" (HAMILTON, 2004, p. 18). Portanto torna-se extremamente necessária a notação da coreografia quando se trata de vassourinhas.

\subsection{Vassourinhas no repertório contemporâneo}


Do século $X X$ até os dias atuais, compositores de música orquestral não se preocupam com o gesto do percussionista/baterista mas sim com o resultado sonoro final, apenas notando o essencial rítmico assim como na notação Motif da dança, que só notava os movimentos principais do(a) bailarino(a). George Gershwin, por exemplo, em sua Rhapsody in Blue faz uso das vassourinhas mas não indica a forma de percussão:

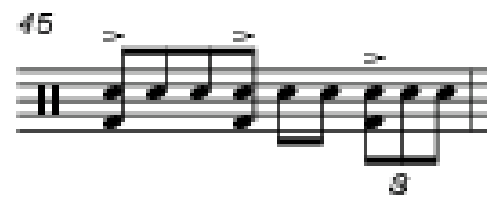

Fig. 8: Extraído da parte de percussão de Rhapsody in Blue ((GERSHWIN, 1938, p.11).

Da mesma forma, Leonard Bernstein em sua abertura do musical West Side Story procede da mesma forma. Casey Cangelosi, percussionista e compositor, em sua peça de caixa Sleight of and Evil Hand, composta para o Atlanta Symphony Orchestra Modern Snare Drum Competition, também faz uso de uma notação mais simplificada com algumas ligaduras e traços para indicar a escovação e símbolos de giro da vassourinha para tocar com o anel da haste no topo do metrônomo.

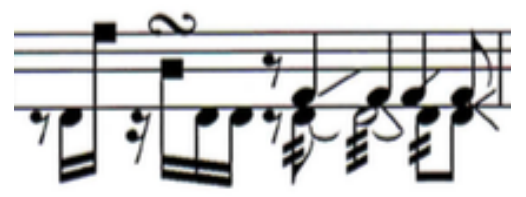

Fig. 9: Notação na partitura Sleight of and Evil Hand de C. Cangelosi para ser tocada com vassourinhas. 
O próprio compositor gravou um vídeo (CANGELOSI, 2003) de sua interpretação da peça com a intenção de divulgá-la e fornecer uma plataforma a mais para a documentação da mesma.

Podemos também observar uma forte tendência de utilização das vassourinhas no repertório voltado para o jazz, contexto onde surge as vassourinhas na música moderna. Porém, em grande parte das composições, não por desleixo mas por falta de informação a respeito desta ferramenta, deixa-se de usufruir de grandes possibilidades tímbricas que vassourinhas tem a oferecer.

\section{Os livros didáticos sobre vassourinhas nos E.U.A.}

Os sistemas de notação são bem variados nos métodos que pretendem ensinar a arte de tocar com vassourinhas, mas podemos observar uma tendência de solidificar algumas formas de escrita em determinados casos. Abaixo estão alguns dos principais livros com tal finalidade:

1. Brush Artistry de Philly Joe Jones;

2. Brush Fire de Kirk Willis;

3. Brushworks de Clayton Cameron;

4. Contemporary Brush Techniques de Louie Bellson, Henry Bellson e Dave Black;

5. Mastering The Art of Brushes de Jon Hazila;

6. The complete Guide to Playing Brushes de Florian Alexandro-Zorn;

7. The Sound of Brushes de Ed Thigpe.

Vamos analisar três deles, The Sound of Brushes de Ed Thigpe, Brush Fire de Kirk Willis e Brushworks de Clayton Cameron, destacando suas diferenças da abordagem de escrita.

\subsection{The Sound of Brushes}


Ed Thigpen usa uma forma de escrita que foi muito comum durante muitas décadas. A exemplo do livro de Philly Jo Jones, ele usa dois planos para exemplificar seus padrões rítmicos:

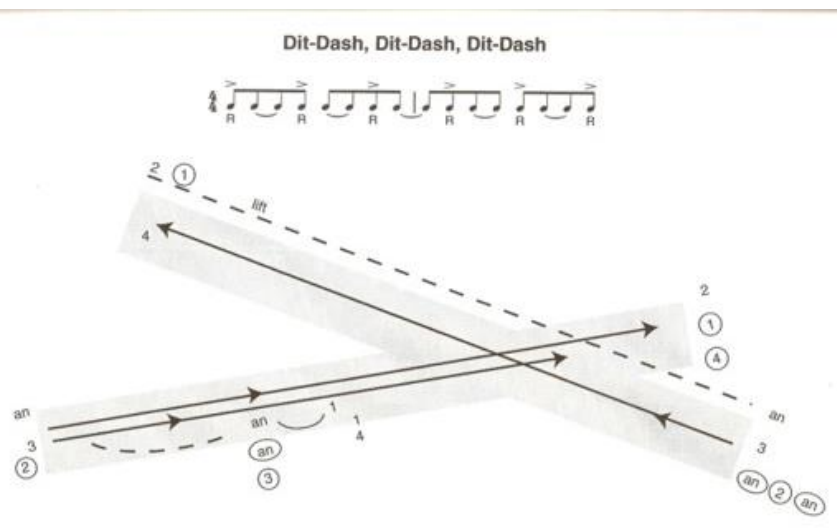

Fig. 10: Padrões rítmicos (THIGPEN, 1999, p. 47).

Extraído do livro The Sound of Brushes (THIGPEN, 1999, p. 47), a figura 10 mostra o plano da escrita musical com o ritmo em dois compassos quaternários e o plano do gráfico onde desenha com setas, números e letras para demonstrar os movimentos das mãos. Thigpen utiliza também outro tipo de notação mesclando figuras musicais nos gráficos. 


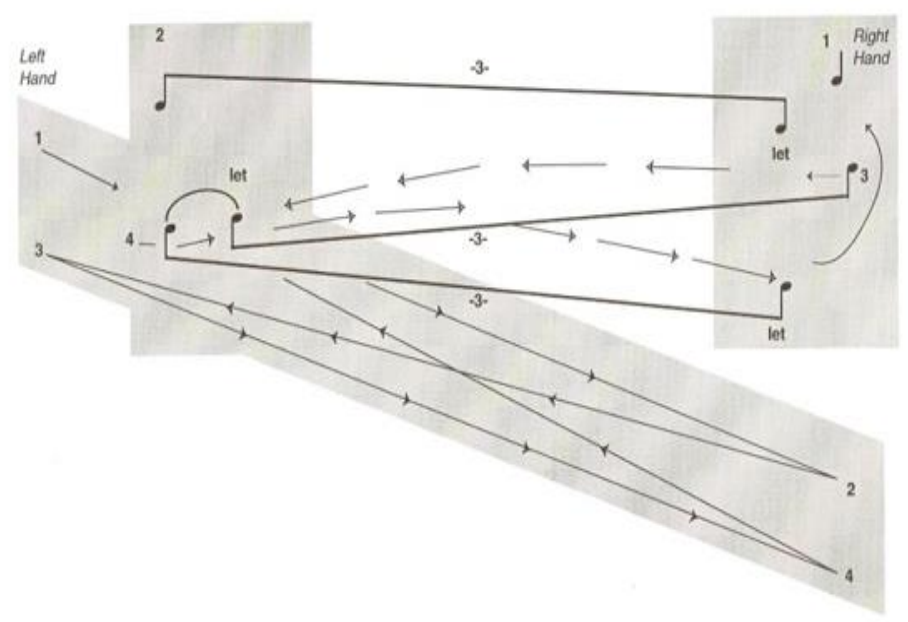

Fig. 11: Notação que mistura figuras musicais e gráficos (THIGPEN, 1999, p. 18).

The Sound of Brushes é um livro excepcional que aborda as escovações e outras movimentações na pele, ou sobre ela. Porém, tornase pouco claro quando ilustra ritmos com toques verticais com mãos alternadas e também quando aborda dois movimentos que se cruzam em um mesmo desenho.

\subsection{Brush Fire}

Kirk Willis, no livro Brush Fire (1997), aborda a escrita aqui de uma forma mais integrada. Ele coloca a escrita musical entremeada com linhas ou setas que demonstram o perfil do desenho que deve ser feito pelas escovações. 
16 The left hand motion slows to allow two counts for each circle

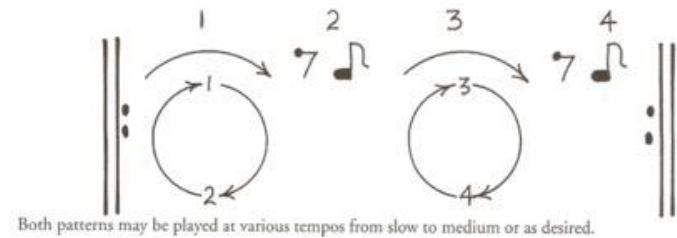

CIRCLE/FIGURE EIGHT PATTERN

This technique for playing boch ballads and medium tempos is called the Circle/Figure Eight pattern. The leff hand in continuous motion completes a small circle, 1) a larger circle; 2) a small circle; 3) and a larger circle; (4) in 4) 4 meter the partern of the left hand resembles the following diagram.

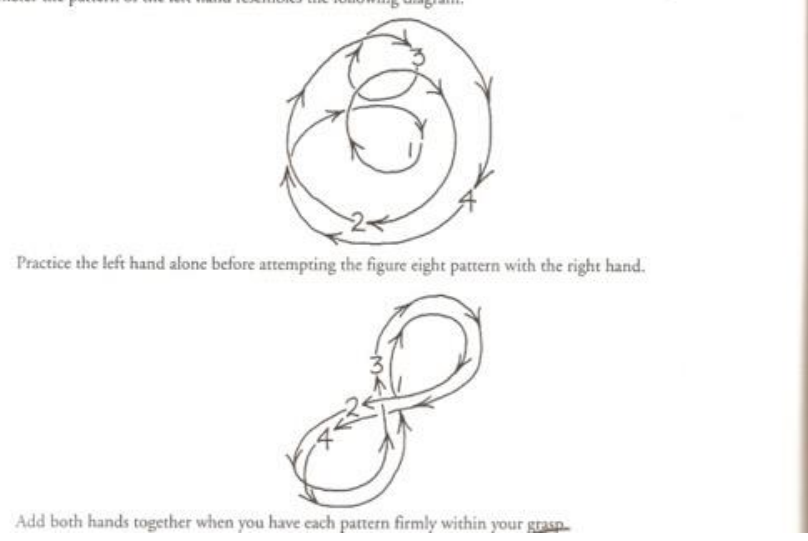

Fig. 12: Exemplo de levada usada por Willis Kirk (1997, p. 16).

Logo abaixo, Kirk exemplifica o movimento do "Oito" muito usado em músicas bem lentas. É possível ver que é bem parecido com os mapas de movimentação dos bailarinos na Labanotation ou Beauchamps-Feuillet do séc. XVIII. 


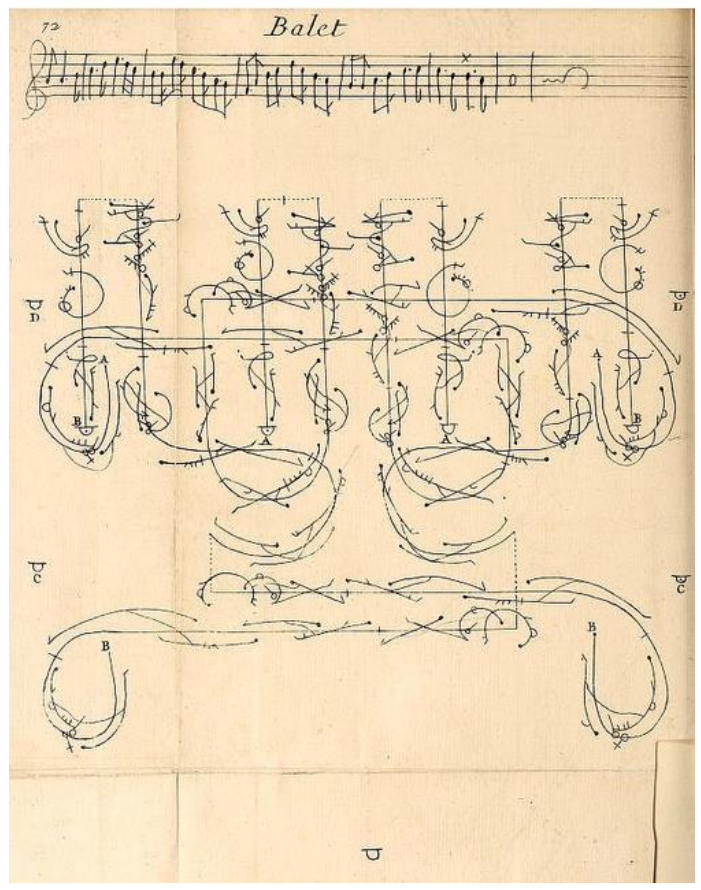

Fig. 13: Amostra da movimentação de bailarinos com notação de Beauchamps-Feuillet (FEUILLET, 1700, p. 72).

Em alguns momentos Kirk usa também a escrita musical misturada com desenhos, substituindo até as cabeças de nota por setas.

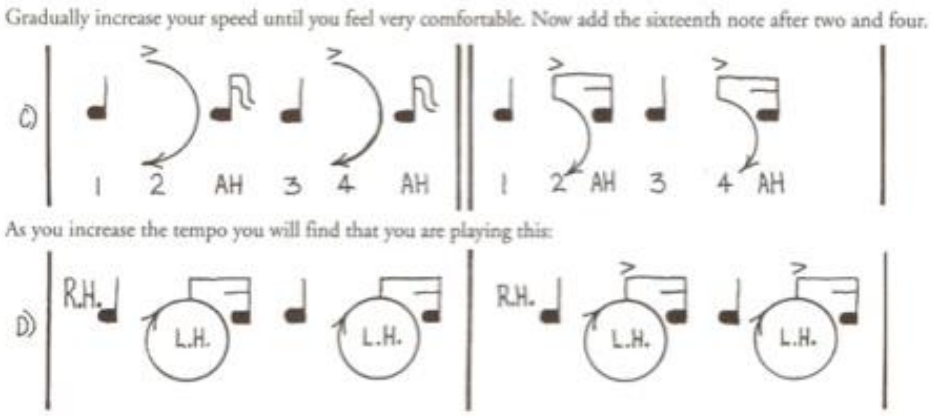

Fig. 14: Exemplo de escrita substituindo as cabeças de nota e hastes por setas (KIRK, 1997, p. 30). 
Finalmente, para demonstrar figuras ligadas que atravessam a barra de compasso, desenha uma linha perpassando a barra e ligando dois círculos em compassos diferentes.

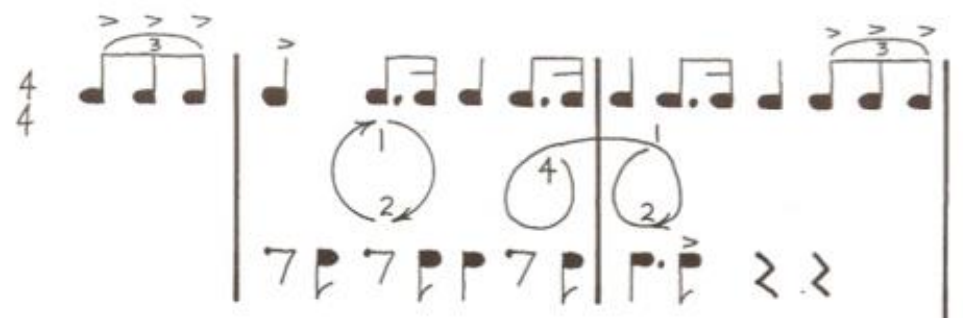

Fig. 15: Extraído do livro Brush Fire de Willis Kirk (1997, p. 45).

Esse método se mostra bem eficiente, embora use um espaço visual muito amplo, fazendo com que em alguns casos se leia uma parte de cada vez, como por exemplo, quando se tem a necessidade de acrescentar a linha do bumbo.

\subsection{Brushworks}

Cleyton Cameron dá um salto muito grande no que diz respeito à escrita para vassourinhas, pois ele reúne o que os livros precedentes tem de melhor e os adapta, adicionando uma variedade de toques e escovações. Ele já utiliza de forma mais concreta a escrita no pentagrama e desenvolve conceito de sustentação e duração com as próprias cabeças de nota e ligaduras. Cada cabeça de nota é uma mudança de direção, por consequência também representa mudança de ritmo, e a ligadura indica que a vassourinha não sai da pele para essa mudança. Se a escovação tiver de seguir na mesma direção quando uma ligadura de valor for usada na troca de compasso ou numa figura sincopada, um símbolo de continuidade é usado (uma linha sobre duas cabeças de nota). 


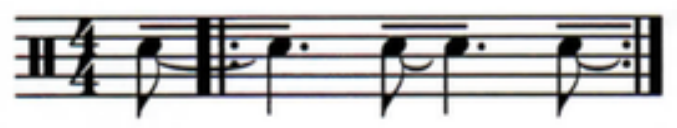

Fig. 16: Notação de escovações (CAMERON, 2003, p. 128).

Somente utiliza os gráficos para explicar o que acontecerá no padrão que está escrito, ou seja, o desenho não faz parte da partitura. Usa graduações de preto e cinza nos gráficos que acompanham a partitura para indicar mais ou menos pressão das cerdas sobre a pele.

Dia. 2

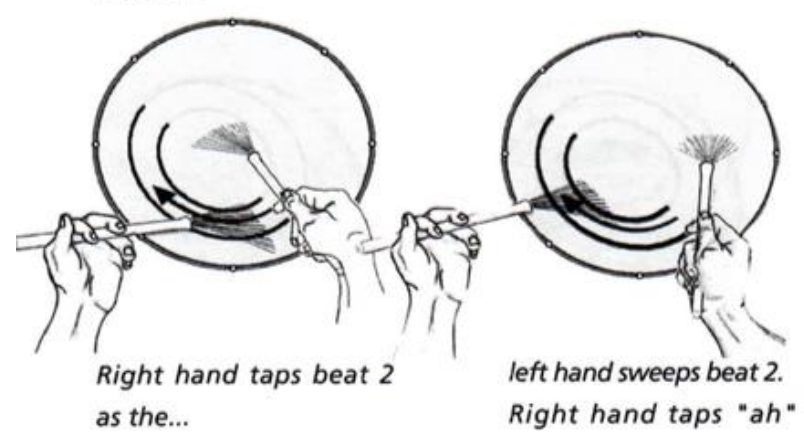

Fig. 17: Notação com gráficos de escovações (CAMERON, 2003, p. 27).

Cameron também usa símbolos musicais já existentes e utilizados na linguagem percussiva como setas, por exemplo, que entram como fator determinante para o músico se orientar. A posição das mãos direita e esquerda no pentagrama segue a tradicional posição caixa e chimbal já usada há anos pelos bateristas. 


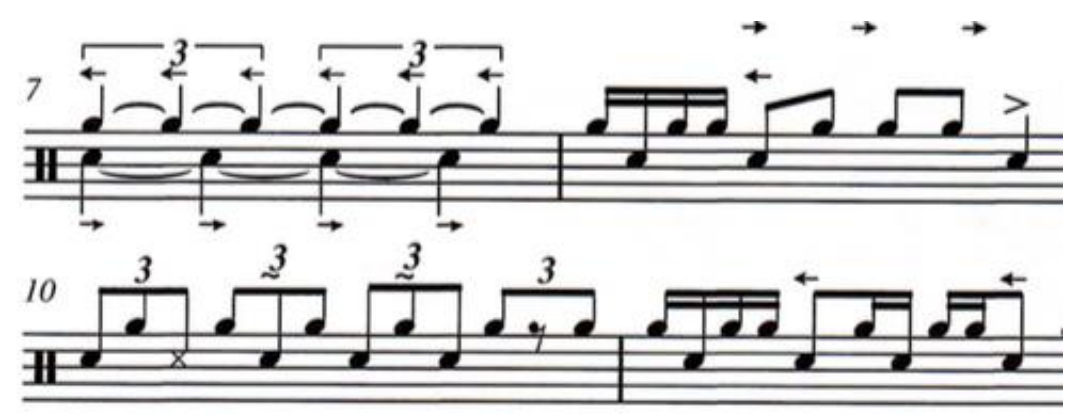

Fig. 18: A figura mostra posicionamento das mãos no pentagrama (CAMERON, 2003, p. 118).

Vemos que os elementos sonoros da vassourinha também foram aumentando com o passar do tempo. Conforme os músicos foram se familiarizando com ela e os próprios fabricantes foram desenvolvendo novos materiais para sua confecção, foram surgindo novas possibilidades. Com isso a forma de notação também ganhou uma grande variedade principalmente depois de Cameron, que ampliou a escrita para o flex, rim roll e clasping. Então entram em cena os acentos diversos e símbolos representantes de rulos e outros que ele mesmo cria.

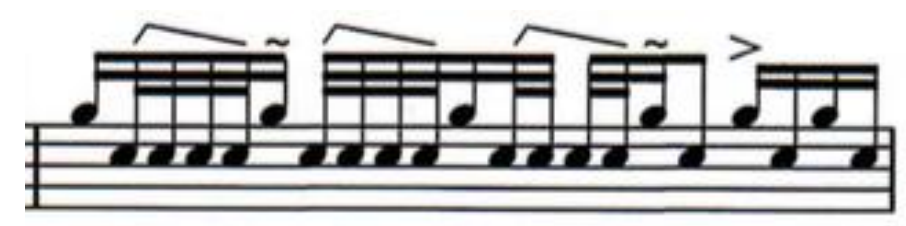

Fig. 19: Notação de toques especiais como o flex e o rim roll (CAMERON, 2003, p. 118).

A notação das escovações que normalmente são mais complicadas de se escrever estão resolvidos de uma maneira muito simples. Como mudança de direção gera ritmo, cada cabeça de nota que aparecer é uma 
direção nova. Os desenhos (circulares ou retos) são definidos antes de começar a leitura.

No fim do livro podemos encontrar algumas transcrições e solos originais escritos com sua grafia, o que a torna útil e aplicável em diversos contextos.

\section{Os livros didáticos sobre vassourinhas no Brasil}

A partir dos contatos dos bateristas brasileiros com os bateristas de jazz norte-americanos, a vassourinha começou a ser utilizada também para tocar samba e posteriormente bossa nova. "Em certa medida, a bossa nova realmente sofreu influência do estilo cool jazz em vários aspectos, como por exemplo, pela redução de instrumentos acompanhantes, gerando uma diminuição do volume do arranjo, sobressaindo, assim, o arranjo musical e, por conseguinte, a voz condutora" (BOLLOS, 2010, p. 124). A transmissão desse conhecimento era feita apenas por via oral, de bateristas para bateristas que aprendiam de discos ou de ver apresentações. Graças a alguns didatas como Oscar Bolão (2003), Ramon Montagner (2007) e Nelton Essi (2013), hoje temos escritos alguns dos padrões usados pelos bateristas brasileiros até hoje.

\subsection{Vassourinhas na Música Brasileira}

Ramon Montagner foi o pioneiro em elaborar uma aula em vídeo sobre vassourinhas no Brasil. Lançado em 2007, seu DVD tem por objetivo ensinar padrões de vassourinhas no samba e na bossa nova com uma pequena demonstração de baião, maxixe e samba batucada ao final. No decorrer do vídeo, passa também alguns padrões de coordenação com baquetas e pé esquerdo no chimbal. Este trabalho não foi lançado em livro, no entanto o que temos é um arquivo em vídeo e algumas notações que aparecem na tela como reforço do que se ouve. Temos a escrita rítmica 
do que deve ser tocado e solucionamos o restante do movimento pelo movimento que vemos no vídeo.

Sua notação não apresenta muitas inovações e nem sempre diferencia os toques verticais dos horizontais. Por outro lado mantém a mão direita escrita acima da esquerda, com dois pentagramas, como uma partitura de piano. Ele usa também pequenas flechas para indicar sentido. Extraído do DVD Vassourinhas na Música Brasileira de Ramon Montagner, a figura a seguir (fig. 20) é uma fotografia da tela em que mostra a escrita de um exercício utilizando duas mãos com vassourinhas:

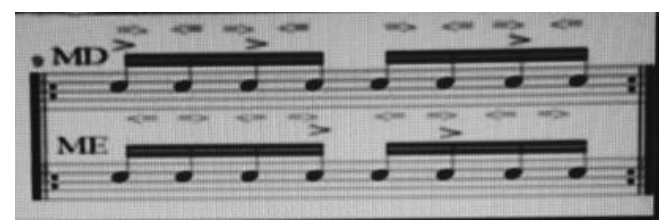

Fig. 20: Escrita de exercício utilizando duas mãos com vassourinhas (Montagner, 2007).

Para notar o flex, usa-se um " $z$ " sobre a haste da nota para representar o pequeno rulo.

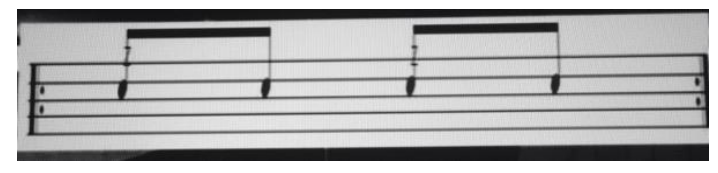

Fig. 21: Fotografia da tela em que mostra a escrita do flex na primeira colcheia (Montagner, 2007). 
No livro Batuque é um privilégio (2003), Bolão inclui as vassourinhas entre os vários instrumentos de percussão que aborda. Explicando as batidas de bossa nova, usa duas vozes, uma para cada mão e coloca dois símbolos para indicar escovação para os lados direito e esquerdo. Ele marca os ritmos e acentos essenciais e não especifica os sentidos da escovação, mas coloca um traço na haste para indicar a raspagem na pele, como mostra a figura 22 a seguir:

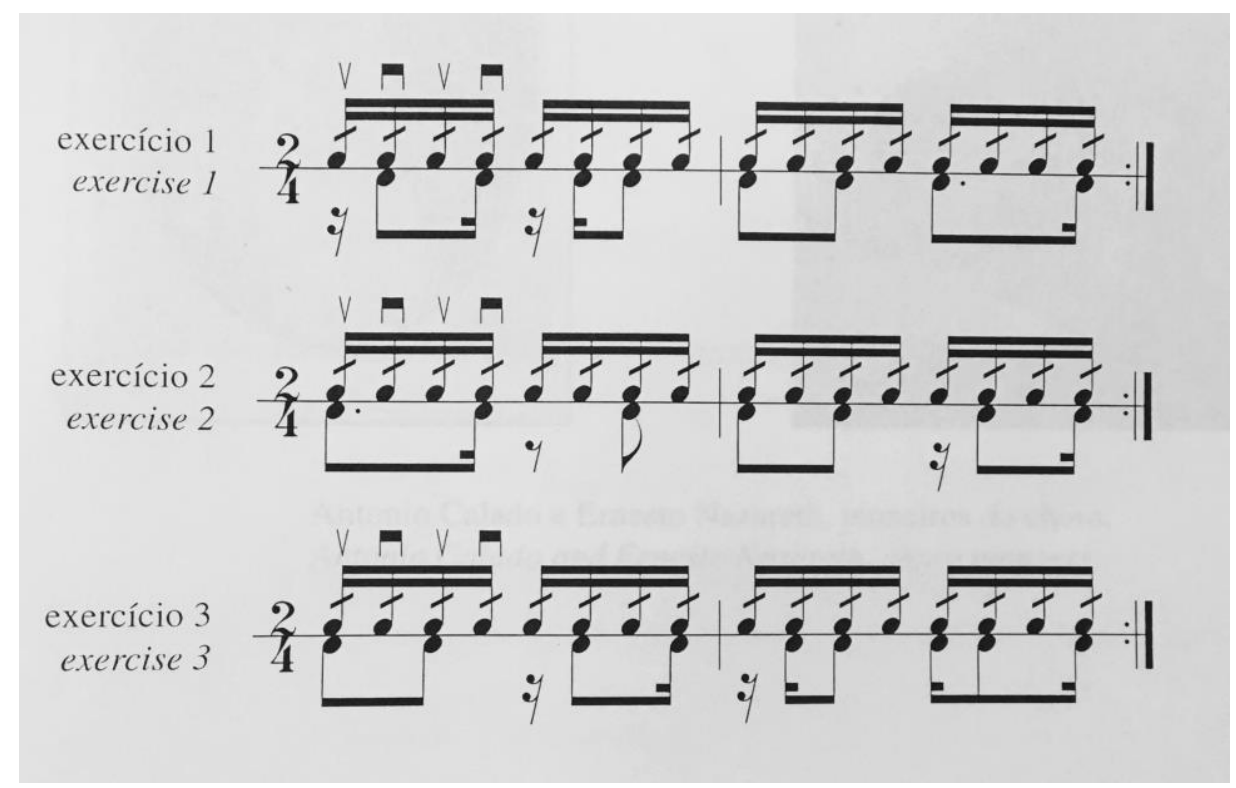

Fig. 22: Padrão de Choro para vassourinhas (BOLÃO, 2003, p. 101).

\subsection{Vassourinhas Brasileiras}

O método Vassourinhas Brasileiras de Nelton Essi também não foi lançado em livro, porém encontramos disponível para download em arquivo PDF (disponível em www.neltonessi.com). O arquivo PDF é organizado com transcrições dos padrões mostrados no DVD na mesma ordem em que ali aparecem. Separa em seções dos ritmos bossa nova, 
samba e samba rápido. Depois vem os nordestinos baião, ijexá, frevo e maracatu.

Primeiramente, vale observar a tentativa de colocar todas as informações como ritmo, movimento e tipos de toque no mesmo plano. No começo apresenta uma legenda que explica cada item da escrita: posição das mãos, sinais para sentido e forma das escovações, tipos de toque abafamento da pele. Definem-se os toques verticais com notas sem cabeça, escovações com notas com cabeça cheia, toques especiais como flex, rim roll, flat, agarre (chamado de clasping por Cameron) como em figura a seguir:
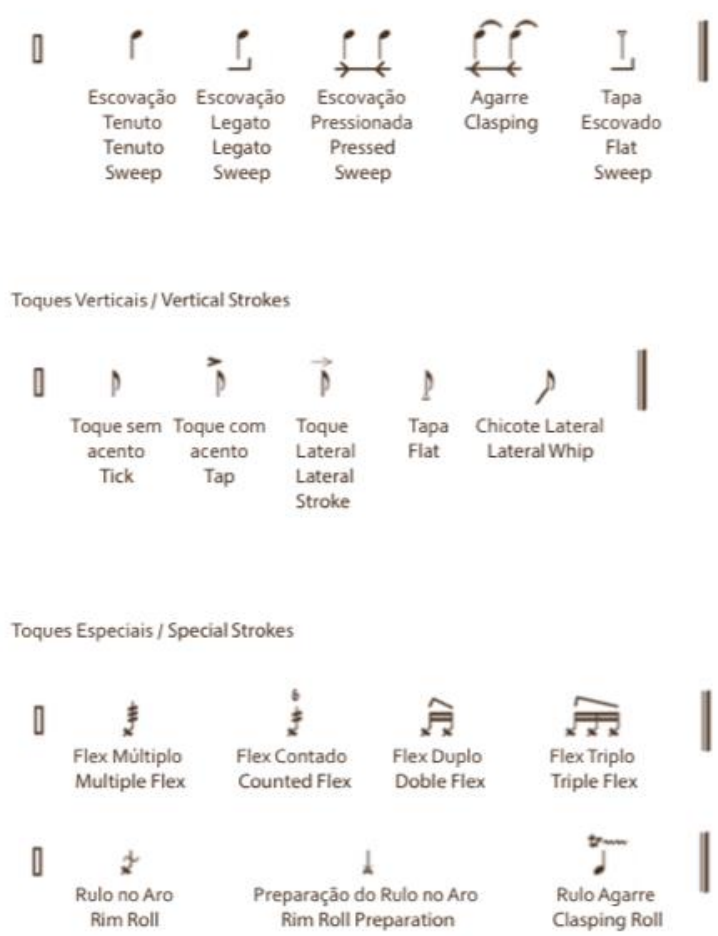

Fig. 23: Parte da legenda para PDF de Vassourinhas Brasileiras de Nelton Essi (2013, p. 2). 
Como Willis Kirk (1997, p. 10), Essi coloca tudo num mesmo plano, porém de uma forma mais limpa e num campo visual menor. As linhas de sustentação são a inovação desta escrita. Como marcações de pedal de piano, indicam que as vassourinhas não saem da pele, o que já se diferencia das linhas pontilhadas ou de outra cor dos gráficos de outros livros. Se a barra não está presente, entendemos que a vassourinha não permanece na pele após o toque. Na primeira página há alguns padrões de bossa nova que usam formatos de $S$ e 8 que são indicados antes da barra de sustentação o que dispensa o desenho do gráfico-pele, um espécie de círculo redondo que representa a pele acompanhado de desenhos representando as escovações e toques, e estas superfícies são indicadas quando usadas.

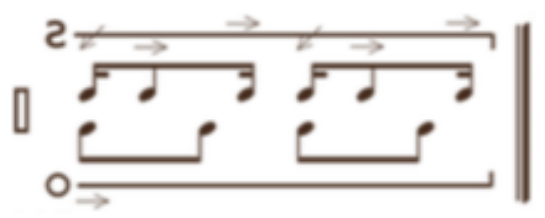

Fig. 24: Grafia das escovações (ESSI, 2013, p. 7).

Quando as escovações são retas, apenas é indicado o sentido (esquerda ou direita) com setas sobre a barra, como mostra a figura 25 :

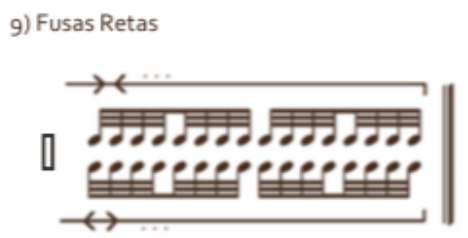

Fig. 25: Padrões de bossa nova (ESSI, 2013, p. 7). 
É importante notar a ausência de linhas como as de um pentagrama nos exercícios iniciais. Poderia ser usada uma linha de separação entre as duas mãos, mas não se faz necessário pela clareza com que essas informações se apresentam na partitura. No final do arquivo PDF, apresenta dois solos em que usa o pentagrama e as duas vozes (mão esquerda e direita) unidas pelos mesmos colchetes, no entanto, permanece a diferenciação de altura para discernimento das mesmas.
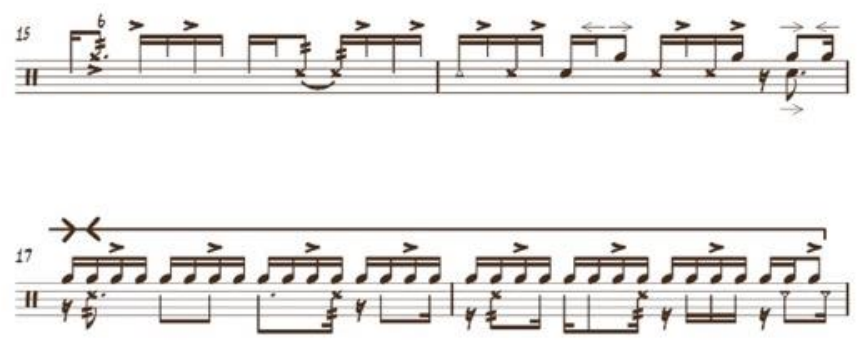

Fig. 26: Trecho da peça "Ohayo" (ESSI, 2013, p. 20).

Em Vassourinhas Brasileiras podemos notar uma preocupação como a de Laban ou Benesh de notar detalhadamente cada movimento feito no decorrer de uma execução musical.

\section{Vídeo X Escrita}

Com o surgimento da gravação audiovisual ficou muito mais rápido e prático o registro de movimentos em geral, incluindo aí as coreografias dos balés, uma história contada por atores, interpretação da mensagem de uma música, a atualização das notícias do jornal atual ou movimentos de uma vassourinha sobre a pele da caixa e outras superfícies do instrumento de percussão. Porém, sobre isso, o artigo Tutoring System for Dance Learning diz: 
Recording mediums such as VHS and DVD can provide a quicker and cheaper means of acquiring and storing a dance. However, to capture the complete stage requires a camera to be either set back, making the dancers very small or include close- ups resulting parts of the dancers or choreography being missed or obscured. Professionally made recordings for televisions, video and DVD can capture many great productions with world-class dancers; however, the 2D camera viewpoint is subject to the director's interpretation. Also, searching these collections of digital data to learn the dance movements is tedious because of the huge volume of data'. (KANNAN, R.; ANDRES, F.; RAMADOSS, 2009, p. 2)

Acreditamos que com um aluno de bateria o mesmo caso se aplica. Por maior que sua tela de televisão ou do computador seja, fica praticamente impossível prestar atenção em todos os detalhes de todos os ângulos mostrados ao mesmo tempo, podendo tornar o aprendizado lento e tedioso.

\subsection{Vídeo-aulas sobre vassourinhas}

Há alguns vídeos importantes que podem servir como material de apoio ao aprendizado. A ideia é que o músico/baterista aprenda todos os movimentos essenciais, neste caso com as vassourinhas, para então ter

\footnotetext{
1 Mídias de gravação como VHS e DVD podem fornecer um meio mais rápido e mais barato de adquirir e armazenar uma dança. No entanto, para capturar o estágio completo, é necessário que a câmera seja retrocedida, deixando os dançarinos menores ou incluindo close-ups, fazendo com que partes dos dançarinos ou coreografias sejam perdidas ou obscurecidas. Gravações feitas profissionalmente para televisões, vídeo e DVD podem capturar muitas produções excelentes com dançarinos de classe mundial; no entanto, o ponto de vista da câmera 2D está sujeito à interpretação do diretor. Além disso, pesquisar essas coleções de dados digitais para aprender os movimentos da dança é entediante devido ao grande volume de dados.
} 
um pano de fundo razoável para interpretação dos também já aprendidos símbolos musicais específicos, que no entanto é exatamente o que se passa com qualquer outra interpretação musical.

Dentre os principais vídeos sobre o assunto estão o The Essence of Brushes de Ed Thigpen (1991) e Brushworks de Clayton Cameron (2006) na área do Jazz, The Brush Secret de Florian Alexandru-Zorn (2010) na música pop e Vassourinhas na Música Brasileira de Ramon Montagner (2007) e Vassourinhas Brasileiras de Nelton Essi (2013) na área de rimos brasileiros. E ainda o vídeo Brush Control: The key to mastering brushes de Jon Hazilla (2000), The Ultimate Drummer's Workout de Ted Makenzie (2006) e The Art Of Playing With Brushes apresentado por Adam Nussbaum e Steve Smith (2007).

\section{Considerações finais}

Observamos que a evolução da escrita da língua, da dança ou da música, passando pelas vassourinhas se dão independentemente, porém de forma significativamente parecida. A necessidade da perpetuação/transmissão de informações é inerente à evolução do ser humano e de suas formas de comunicação, seja sonora ou gestual. A forma com que esta notação é feita também se transforma. Desde rabiscos em cavernas, em papiros, em papéis com uma caneta, numa impressora de Gutemberg, numa tela de computador ou num tablet. Sempre reinventaremos as formas de escrever e ler. Portanto, é necessário compreendê-las para nos relacionarmos com as ferramentas antigas e atuais e, se necessário numa etapa futura, contribuir para sua evolução.

Analisando todos esses métodos de escrita, podemos observar que há uma tendência dos principais procedimentos permanecerem com o passar do tempo e evolução da linguagem. Embora cada músico queira imprimir sua personalidade também na escrita, vemos que as pequenas variações de um para outro tendem a gerar novos símbolos e significados. Fazem isso mesmo sabendo que podem correr o risco de suas obras 
ficarem inéditas por conta de sua complexidade e especificidade. Como exemplo, podemos citar a obra de Pierre Conté que "continua a ser desconhecida, porque necessita de meios cênicos e de orquestras essenciais" para serem executadas (TRINDADE, 2008, p. 56). A escrita para percussão também tem esse perfil de desenvolvimento, vista a grande variedade de instrumentos e combinações entre eles, como por exemplo numa montagem de percussão múltipla de Carlos Stasi ou de lánnis Xenákis. Apesar disso, nesse contexto, muitas formas de escrita tornamse standards e os "neossimbolismos" surgem apenas para as inovações.

Ainda hoje se faz necessário o registro deste material musical em meios escritos para utilização simultânea em apresentações e métodos de estudo. Sabendo decifrar o material escrito o estudante pode também desprover-se da necessidade de decorar repertórios extensos e assim preocupar-se com a interpretação musical. Dessa forma, a memorização torna-se secundária ou parte de uma outra fase do aprendizado musical.

\section{Referências}

BELLSON, Louie; BELLSON, Henry; BLACK, Dave. Contemporary Brush Techniques. 2a Edição. Califórnia: Alfred Publishing Co. Inc, 2000. 47p.

BOLÃO, Oscar. Batuque é um privilégio. Rio de Janeiro: Lumiar Editora, 2003.

BOLLOS, Liliana Harb. Bossa Nova e crítica: polifonia de vozes na imprensa. São Paulo: Annablume, 2010.

CAMERON, Clayton. Brushworks: The DVD. [Filme-vídeo]. Carl Fisher. New York, 2006. DVD duplo. Duração: 117 min.

CAMERON, Clayton. Brushworks: the new language for playing brushes. New York: Carl Fisher, 2003. 128p. 
CANGELOSI, Casey. Sleight of and Evil Hand: for solo snare drum and methronome. West Virginia: Cangelosi Publications. 2013. (partitura).

CANGELOSI, Casey. Sleight and Evil Hand: for solo snare drum and methronome. West Virginia: Cangelosi Publications. 2013. (Vídeo). Disponível em: <https://www.youtube.com/watch?v=1htzcRnWPaY>. Acesso em: 28 mai. 2013.

CONTÉ, Pierre. Etats libres. Disponível em: http://conte.notation.free.fr/Tableau\%20Synoptique\%20Conte.pdf. Acesso em: 29 de mai 2018.

ESSI, Nelton. Vassourinhas Brasileiras Produção Independente. São Paulo, 2013. DVD. Duração: 180 min. (Filme-vídeo)

ENCYCLOPAEDIA BRITANNICA. Dance notation. Disponível em: https://www.britannica.com/art/dance-notation. Acesso em: 23 de mai. 2018.

ENCYCLOPAEDIA BRITANNICA. Schrifttanz. Disponível em: https://www.britannica.com/topic/Schrifttanz. Acesso em: 20 de mai. 2018.

FEUILLET, Raoul-Auger, livro Choréografie ou l'art d'écrire la dance par caractères, figures et signes démonstratifs, avec lesquels on apprend de soy même toutes sortes de dances Paris, 1700. Disponível em: http:/ / www.libraryofdance.org/manuals/1700-FueilletChoregraphie_(BNF).pdf. Acesso em: 20 de mai. 2018.

GERSHWIN, George. Rhapsody in Blue. New York Philharmonic Leon Levy Digital Archives. $1938 . \quad$ Disponível em: https://archives.nyphil.org/index.php/artifact/cca8cdb3-87d8-4618- 
a844-8a1988d01140-0.1/fullview\#page/12/mode/2up. Acesso em: 20 de mai. 2014. (partitura).

HAMILTON, Jeff. You've got to be pretty when you play brushes. Estados Unidos, Percussive Notes, v. Fevereiro, 2004.

HAZILLA, Jon. Brush Control: The Key to Mastering Brushes. Milwalkee: Hal Leonard Corporation, 2008.

HAZILLA, Jon. Mastering The Art of Brushes. Massachusetts: Berklee Press, 2000. 53p.

JONES, Philly Joe. Brush Artistry. Leicester, England: Premier Drum Company Limited. 1968. 18p.

KANNAN, R.; ANDRES, F.; RAMADOSS, B. Tutoring system for dance learning. Patiala, India: IEEE, International Advance Computing Conference (IACC'09). 2009. Disponível em: <http://arxiv.org/abs/1001.0440>. Acesso em: 28 dez. 2014.

KIRK, Willis. Brush Fire: an innovate method for the development of brush technique. Texas: Houston Publishing Inc., 1997. 60p.

MACKENZIE, Ted. The Ultimate Drummer's Workout: For all Drummers. New York: Amsco Publications, 2006.

MCGUINNESS-SCOTT, Julia. Movement Study and Benesh Movement Notation. Oxford: Oxford University Press, 1983.

MONTAGNER, Ramon. Vassourinhas na Música Brasileira. Produção Independente Giba Favery e Emerson Jordão. São Paulo, 2007. DVD. Duração: 58 min. (Filme-vídeo) 
NUSSBAUM, Adam; SMITH, Steve. The art of Playing with Brushes. Produção de Hudson Music. New York, 2007. DVD duplo. Duração: 7 horas e 16 min. (Filme-vídeo)

SUTTON, Valerie. A colection of classical ballet variations. Book one. The Sutton Movement Writing Press. La Jolla. CA. USA. 1983. Disponível em: http: / / www.dancewriting.org/acrobat/ballet/Collection_Ballet_Variation. pdf. Acesso em: 29 dez. 2014.

SUTTON, Valerie. O Centro para a Escrita do Movimento de Sutton: Dance Writing. Califórnia, 2004. Disponível em www.movementwriting.org. Acesso em: 20 dez. 2017.

THIGPEN, Ed. The Essence of Brushes. Produção de Interworld Music. Miami, 1991. DVD. Duração: 61 min. (Filme-vídeo)

THIGPEN, Ed. The Sound of Brushes. Florida: Warner Bros, 1999. 59p.

TRINDADE, Ana Lígia. A escrita da dança: a notação do movimento e a preservação da memória coreográfica. Canoas: Ed. ULBRA, 2008. 144p.

ZORN, Florian Alexandru. The complete Guide to Playing Brushes: Brush skills for playing Jazz and Pop Music. Cologne: Alfred Music Publishing $\mathrm{GmbH}, 2010.146 \mathrm{p}$. 